\title{
A IMPORTÂNCIA DO MATERIALISMO HISTÓRICO NA FORMAÇÃO DO EDUCADOR DO CAMPO
}

\author{
Luiz Bezerra Neto ${ }^{1}$ \\ Maria Cristina dos Santos Bezerra ${ }^{2}$ \\ Agência financiadora: FAPESP
}

\section{RESUMO}

Apontamos neste texto a importância do domínio do método e dos pressupostos teóricos do materialismo histórico para fundamentar o estudo sobre a educação do campo. Tomamos como referência a nossa atuação nos cursos de formação de educadores para este segmento específico, tanto através dos cursos de pedagogia da terra, quanto da formação de professores para atuarem nas classes multisseriadas do campo.

Apresentamos, em linhas gerais, os elementos constitutivos do materialismo histórico e dialético, para em seguida apontarmos a importância e a atualidade desta perspectiva teórico-metodológica, especialmente nas pesquisas em Educação de um modo geral e, particularmente para os estudos sobre educação do campo. Isso nos leva a uma tomada de posição diante da corrente hegemônica na pesquisa em educação e em especial na educação do campo, que tem arrebatado muitos pesquisadores que se deixam levar pelos ventos da pós-modernidade, e embebidos pelas suas idéias, julgam ultrapassados todos os referenciais baseados no paradigma iluminista racionalista instaurado com o advento da modernidade.

Palavras-chave: materialismo histórico, educação do campo, pesquisa em educação

\section{THE IMPORTANCE OF HISTORICAL MATERIALISM IN THE EDUCATOR TRAINING FIELD}

\begin{abstract}
We point in this text the importance of the domain about the method and the estimated theoreticians of the historical materialism to base the study on the education on the field. We take, as reference, our performance in the courses of educators education for this specific segment, as much through the courses of teacher constitution for the land, how much of the formation of professors to act in the multisseriadas classrooms of the field. We present, in general lines, the constituent elements of the historical and dialectic materialism, for after that pointing the importance and the contemporaneity of this theoretician-metodogical perspective, especially about the Education research in a general way and, particularly, for the studies on education in the field. This takes to a taking of position of the hegemonic chain in the research in education and especially in the education of the field, which has involved many researchers that get themselves leaded by the winds of after-modernity, e absorbed by its ideas, the reference system based on the restored rationalist paradigm, introduced with the advent of modernity.

keywords: historical materialism, education of the field, search in education.
\end{abstract}

O texto aqui apresentado trata da importância do materialismo histórico na formação do educador que atua no campo e tem por objetivo apontar algumas discussões sobre a educação do homem rural ou, como prefere alguns, do camponês, que segundo os movimentos sociais de luta pela terra deve se dar no campo, bem como discutir a importância do domínio do método e dos pressupostos teóricos do materialismo histórico 
para fundamentar o estudo sobre a educação que ocorre nesse meio, sobretudo no momento em que atuamos nos cursos de formação de educadores para este segmento específico, quer através dos cursos de pedagogia da terra, quer através da formação de professores para atuarem nas classes multisseriadas do campo, como propõe o Programa Escola Ativa.

O conhecimento do método se faz necessário quando alguns setores da academia, juntamente com a maioria dos movimentos sociais defendem que os cursos voltados para a formação de educadores do campo tenham por objetivo a transformação social, visando a construção de uma sociedade igualitária, baseada nos princípios do homem novo proposto por educadores socialistas como Makarenko e Pistrak, para quem a escola deveria estar a serviço da classe trabalhadora.

Para início do debate apresentamos, em linhas gerais, os elementos constitutivos do materialismo histórico e dialético, para em seguida apontarmos a importância e a atualidade desta perspectiva teórico-metodológica, especialmente nas pesquisas em Educação de um modo geral e, particularmente para os estudos sobre educação do campo. Isso nos leva a uma tomada de posição diante da corrente hegemônica na pesquisa em educação que tem arrebatado muitos pesquisadores que tem se deixado levar pelos ventos da pós-modernidade, e embebidos dessas suas idéias, "julgam ultrapassados todos os referenciais baseados no paradigma iluminista racionalista instaurados com o advento da modernidade" (BEZERRA NETO e COLARES, 2002).

Ao discutir o surgimento do pensamento materialista retomamos os filósofos da natureza, vulgarmente chamados de pré-socráticos, visto que desde o momento em que o homem inicia suas primeiras especulações filosóficas em busca de decifrar a si e ao universo, este tem procurado de alguma maneira encontrar as explicações da causa primeira (ontologia) do cosmos e da vida que tem se constituído em objeto de profundas divergências, tendo por centro a discussão em torno do que seria o determinante; o ser, isto é, a matéria ou o pensamento, a idéia. Os idealistas sobrepõem o espírito à natureza acreditando, em última instância, na criação do mundo; já os materialistas vêem a natureza como o elemento primordial sendo, a consciência, ela mesma, um produto da matéria altamente organizada.

Quanto à origem da dialética, lembramos que esta forma de pensamento remonta aos pensadores da antigüidade clássica, dado que filósofos como Heráclito de Éfeso (540 a.C.), já a concebia como o modo de compreensão da realidade essencialmente contraditória e em permanente transformação. Porém, é em Hegel (1770-1831) que a dialética adquire acentuada importância enquanto método de investigação, muito embora consubstanciada, no plano ontológico, em uma concepção idealista. Marx (1818-1883) e Engels (1820-1895) modificam e superam todo o conhecimento até então acumulado, e dão ao materialismo e à dialética um sentido extremamente significativo.

Nesse sentido, podemos afirmar que o materialismo histórico, desenvolvido por Marx e Engels, funda-se no imperativo do modo social de produção da existência humana. Com base na ideologia alemã podemos assim resumir esta assertiva:

1) A produção dos meios que permitam satisfazer as necessidades humanas é condição básica e indispensável para a existência do homem e de tudo o que ele possa criar; 2) A ação de satisfazer a necessidade inicial e o instrumento utilizado para tal conduzem a novas necessidades; 3) Os homens se reproduzem, o que também dá origem a novas necessidades, dentro de um quadro social; 4) Conseqüentemente, deve-se estudar e elaborar a história dos homens em estrita correlação com a história da indústria e das trocas (MARX e ENGELS, 2007: p. 50-52). 
O método de análise está vinculado a uma concepção de realidade, de mundo e de vida, funciona como mediador no processo de entender a estruturação, o desenvolvimento e a transformação dos fenômenos sociais, dos objetos que investigamos.

Para melhor evidenciar tal fato, é preciso deixar claro que o desenvolvimento da ciência, especialmente a partir da modernidade, revelou a natureza como uma unidade em movimento, constituída de interações complexas e contraditórias. Portanto, a dialética, enquanto elemento da natureza, não foi criada ou inventada pelo marxismo, mas é algo que existe de forma objetiva, independentemente do sujeito, embora só possa ser compreendida numa sociedade humana. Por outro lado, embora seja possível falar de uma dialética da natureza, não faz sentido falar em dialética sem o homem, uma vez que é na interação homem-natureza que se constrói o conhecimento. Como observa LEFEBVRE (1979: 2122) “... só existe dialética (análise dialética, exposição ou 'síntese') se existir movimento; e... só há movimento se existir processo histórico: história. Tanto faz ser a história de um ser da natureza, do ser humano (social), do conhecimento!"

$\mathrm{Na}$ perspectiva de Marx e Engels, o universo e tudo o que há nele tem existência material, concreta, podendo ser racionalmente conhecido. Nesse sentido, o conhecimento produzido objetivamente pelo sujeito, deve ter como meta a reprodução do real, em suas múltiplas determinações. Mas para que isto seja alcançado é preciso ultrapassar o nível da superfície, da aparência imediata das coisas e atingir a essência. Esta é uma tarefa complexa, porque a realidade que nos envolve, apresenta-se como um todo caótico, só nos possibilitando, por meio da abstração, analisar suas partes, através das quais, poderemos reconstruir o concreto real que está na base de todo o conhecimento (BEZERRA NETO e COLARES, 2002).

Através deste método de análise devemos partir sempre do particular para o geral, partindo de um dado empírico, concreto, factual, daí sua importância para compreender os movimentos de luta pela terra e o processo educacional por estes desenvolvidos.

O procedimento consiste em operar simultaneamente em dois níveis de análise: a observação direta e a observação indireta, procurando distinguir entre a aparência e essência. Nesse processo, a relação sujeito-objeto conserva sempre a noção de que o objeto sobre o qual se trabalha é um objeto produzido pelos homens. Isso significa que inevitavelmente o sujeito está auto-implicado no objeto. Não há uma relação de exterioridade, há uma relação de auto-implicação, que não é uma relação de identidade, mas uma relação de unidade. Marx opera sempre com a categoria de totalidade e de contradição, entendendo ser a realidade social um complexo constituído de múltiplos complexos. Isso significa dizer que há em Marx sempre o enorme cuidado com a especificidade das distintas instâncias sociais. Isso impõe a necessidade da mediação enquanto categoria teórica central na compreensão dos fenômenos sociais. (NETTO, 1998: p. 58-60).

Neste sentido é possível afirmar que o que os homens são coincide com a sua produção, tanto com aquilo que produzem como com a forma como produzem. Portanto, a sociedade produz o homem, mas também é produzida por ele. Assim, a consciência é uma abstração da vida real, sendo produto da atividade humana, dai admitir que não é a consciência que cria a vida, mas a vida que, sob condições sociais reais, cria a consciência. É neste sentido que Marx afirma que

A produção das idéias, de representações e da consciência está (...) direta e intimamente ligada à atividade material e ao comércio material dos homens, é a linguagem da vida real. São os homens que produzem as suas representações, as suas idéias, etc., mas os homens reais, atuantes e tais como foram condicionados por um determinado desenvolvimento das 
suas forças produtivas e do modo de relações que lhe corresponde, incluindo até as formas mais amplas que estas possam tomar. A consciência nunca pode ser mais que o Ser consciente; e o Ser dos homens é o seu processo de vida real (...).

Contrariamente à filosofia Alemã, que parte do céu para a terra, aqui parte-se da terra para atingir o céu. Isto significa que não se parte daquilo que os homens dizem, imaginam e pensam, nem daquilo que são nas palavras, no pensamento, na imaginação e na representação..., parte-se dos homens, da sua atividade real. É a partir do seu processo de vida real que se representa o desenvolvimento dos reflexos e das representações ideológicas deste processo vital (...)" (MARX e ENGELS, 2007, p. 4849)

Para o materialismo histórico só é possível pensar a matéria em seu processo de transformação, dessa forma a possibilidade do conhecimento e da verdade histórica não é questão metafísica, uma vez que sua validação ocorre com a prática. Nesta concepção o homem só pode ser entendido como ser social e histórico que, embora determinado por contextos econômicos, políticos e culturais, é também o criador da realidade social e o transformador desses contextos, mediados por sua ação política.

Partindo da compreensão de que a sociedade nada mais é do que o conjunto de relações sociais, Marx observa que enquanto nas sociedades escravista e feudal havia uma relação absolutamente visível entre as classes, por conta do estatuto da desigualdade, na sociedade capitalista as relações entre os homens são veladas, transformadas em relações entre coisas - mercadorias - uma vez que nestas há um estatuto de igualdade (ideário burguês, todos iguais perante a lei), ou seja, a exploração ocorre entre iguais. Cabendo à ciência, à teoria, desvelar essa realidade.

Marx, ao se propor analisar a sociedade capitalista, pretendia possibilitar à humanidade, e ao proletariado em particular, compreender as leis que regem a história para que tivessem um instrumento que possibilitasse a passagem do reino da capacidade para o reino da necessidade. Para ele, o confronto entre a burguesia e o proletariado levaria à desagregação do capitalismo, pois assim como a burguesia foi a classe revolucionária no interior do feudalismo, o proletariado constitui-se na classe revolucionária no interior do capitalismo, na luta pela construção de uma sociedade sem classes. Nos Manuscritos econômicos e filosóficos, afirma que o trabalhador fica mais pobre à medida que produz mais riqueza, e sua produção cresce em força e extensão pois a desvalorização do mundo humano aumenta na razão direta do aumento de valor do mundo das coisas. Eis aí a contradição do capitalismo (BEZERRA NETO e COLARES, 2002).

Para Marx, os homens estabelecem relações determinadas para a produção, e as estabelecem de forma determinada, tanto com a natureza como com outros homens - por exemplo, através da divisão entre trabalho material e trabalho intelectual - sendo a posição dessas relações condicionadas pelo modo de exploração de uns sobre outros. E isto leva a dominação no interior das classes, dado que, até hoje, a história de toda a sociedade, "é a história da luta de classes" (MARX e ENGELS: 1982, p. 106). No entanto, a produção capitalista gera sua própria negação, com a fatalidade de que um processo natural é a negação da negação, o que constitui a dialética. 
Na concepção teórico-metodológica de Marx, o ponto de partida para a análise da sociedade são os indivíduos reais e suas condições de existência, dado que para ele, a forma de organização da sociedade é que produz possuidores de capital ou de mercadorias de um lado e trabalhadores que possuem apenas a força de trabalho de outro, como resultado do desenvolvimento histórico do modo de produção capitalista.

Considerando que a sociedade na qual vivemos permanece estruturada e organizada sob o modo de produção capitalista, podemos afirmar que esta concepção continua válida para todos aqueles que buscam conhecer a realidade e, acima de tudo, transformá-la, empenhando-se no projeto coletivo de construção de uma sociedade firmada sob novas bases, na qual sejam superadas todas as formas de exploração humana, como se propõem a fazer os movimentos sociais que lutam por terra no campo.

Michael Löwy, citando Rosa Luxemburgo, expõe a atualidade do marxismo ao afirmar que:

Os pensadores burgueses, escreve ela com ironia, procurando em vão desde muito tempo um meio de superar o marxismo, não se aperceberam que o único meio verdadeiro se acha no seio da própria doutrina marxista: 'Histórica até o fim, ela não pretende ter senão uma validade limitada no tempo. Dialética até o final, ela carrega em si mesma o germe seguro de seu próprio declínio'. A teoria de Marx corresponde a um período determinado de desenvolvimento econômico e político: 'a passagem da etapa capitalista à etapa socialista da humanidade'. É apenas na medida em que esta etapa for superada, e as classes sociais desaparecerem, que se poderá ir além do horizonte intelectual representado pelo marxismo (LÖWY, 1987, p. 121-122).

Estas constatações, no entanto, não são suficientes para que se decrete o fim da razão moderna, da objetividade e da verdade do conhecimento, como o fazem alguns expoentes da chamada Nova História, na medida em que ignoram ou desqualificam o pensamento historiográfico racionalista, objetivista, engendrado na modernidade. Ao defender a realização de estudos e pesquisas que valorizem a subjetividade, o sentimento, o prazer, o imaginário, o microscópico, o efêmero, ao mesmo tempo negligenciam as preocupações teóricas, filosóficas e metodológicas do fazer história (BEZERRA NETO e COLARES, 2002).

$\mathrm{O}$ advento da necessidade de se trazer novas abordagens, se buscar novos objetos, novos problemas no campo da Ciência e da História, trazem consigo não apenas a crítica ao modelo de análise que busca a verdade histórica e a objetividade do conhecimento, como também reacende o irracionalismo e combate frontalmente o marxismo, apontando a necessidade de sua superação como decorrência inevitável da derrocada do "socialismo real" (BEZERRA NETO e COLARES, 2002).

A partir de então, alguns autores passaram a defender a irracionalidade e valorizar não mais a verdade, mas a versão, a opinião, a "verdade consensuada", subjetivada, ou seja, passou-se a desprezar o conhecimento.

Uma expressão desta irracionalidade, encontramos no texto de Guacira Louro, ao declarar que

Foi, pois, nos depoimentos orais de onze ex-alunas (na sua maioria também ex-professoras), que viveram na escola nas diferentes décadas, que encontramos nossa mais expressiva fonte de pesquisa. Esses depoimentos articularam-se também com outras fontes: jornais e revistas da época, relatórios, currículos e outros documentos da escola, cadernos 
escolares, fotografias, objetos confeccionados e guardados pelas alunas, etc. Tínhamos, portanto, um amplo conjunto de fontes (escritas, orais, iconográficas) que foram cruzadas e comparadas, na realidade não com a intenção de definir os fatos "verdadeiros", mas sim com o objetivo de buscar as diferentes "versões" - já que essa é uma das importantes características da história oral... (LOURO, 1994, p. 29)

Embora vários trabalhos tragam informações valiosas e inéditas acerca do cotidiano de nossas escolas, bem como de práticas educativas não institucionais, assim como revelam-se excepcionais na identificação e exploração de novas fontes, pecam por não permitirem entender as relações entre o particular e o geral, entre o discurso e a prática efetiva, entre o imaginário e a base material concreta, pois partem apenas de "versões" dadas sobre fatos particulares, sem procurar comprovar sua veracidade na práxis social dos indivíduos em questão.

Práxis esta que somente será possível a partir do pensamento marxista, através do qual nos é possível dizer que a emancipação humana, cuja conquista dá-se através da luta de classes, é profundamente educativa, na medida em que aponta para a superação de toda forma de opressão, mantendo, contudo, o aprendizado do modo de vida em sociedade, que caracteriza a humanidade. Diferentemente de outros animais, biologicamente destinados a uma determinada tarefa, a herança genética do homem não garante a vida social, coletiva. É preciso aprender. Daí a educação ser um vínculo entre o conhecimento e ação, de tal forma que: "A história só é possível quando o homem não começa de novo e do princípio, mas se liga ao trabalho e aos resultados obtidos pelas gerações precedentes" (KOSIK, 1976: p. 18).

Reconhecendo-se e aceitando-se a afirmação de que a história deve ser entendida como "a história de lutas de classes" (MARX e ENGELS, 1982, p. 106), cabe ao pesquisador ou ao estudante de forma geral, desvelar os combates que foram travados pelas forças sociais na fase histórica delimitada para o estudo e neste percurso identificar, entender e descrever as formas pelas quais o objeto investigado reflete tais antagonismos.

É neste contexto que teremos que pensar a educação do campo e seu processo de formação, buscando compreender em que sentido a problemática da educação no Brasil tem sido discutida nos últimos anos, sobretudo no que diz respeito às técnicas, conteúdos, formas de avaliação e utilidade daquilo que é veiculado e ensinado nas escolas.

Outra discussão importante é a que trata sobre o projeto educativo dos trabalhadores rurais que lutam pela terra e por melhores condições de vida e de trabalho nas mais diversas regiões do país, principalmente na busca da compreensão das origens das propostas pedagógicas elaboradas e praticadas para e junto ao homem que, habitando no campo, dele retira seus meios de sobrevivência. Estamos falando da denominada educação do campo.

Essa discussão vai se tornando mais importante à medida que o principal movimento de luta e organização dos trabalhadores rurais, a partir do final do século XX e da primeira década deste século, o Movimento dos Trabalhadores Rurais Sem Terra - MST tem defendido a construção de um novo paradigma social, através do binômio reforma agrária/educação. Essa mudança é compreendida por eles, como condição sine qua non, para o desenvolvimento da nação e, ao mesmo tempo, como a possibilidade de diminuição da exploração sobre os trabalhadores, através de uma pedagogia própria para o campo e que tenha como finalidade a fixação do homem no campo, quer através dos assentamentos realizados por meio da reforma agrária, quer pela manutenção dos que aí se encontram. 
A defesa de um projeto de educação rural no Brasil não é nova, insere-se na intensa produção de textos e debates elaborados, sobretudo, a partir da primeira metade do século passado, no entanto, a luta por uma educação do campo, no campo, lugar de moradia de grandes parcelas da sociedade fazem o diferencial entre as propostas ruralistas e as atuais propostas de educação desenvolvidas pelos movimentos sociais do campo.

A proposta pedagógica por meio da qual se pretende radicar o trabalhador rural no campo tornou-se recorrente nos movimentos sociais e principalmente no MST, chegando posteriormente ao Ministério da Educação através da Secretaria de Educação Continuada, Alfabetização e Diversidade - SECAD que defende que o trabalhador do campo deve ser educado no campo por meio de uma pedagogia própria, a chamada educação do campo. Entretanto, há uma diferença substancial entre as propostas: a SECAD tem apostado muito no trabalho desenvolvido pelo Programa Escola Ativa, através do treinamento de professores para atuarem em escolas unidocentes com classes multisseriadas. Este programa não tem o apoio dos movimentos sociais do campo, que o combatem, devido a sua origem no seio de governos reacionários, bem como a forma como ela chegou ao Brasil, com apoio de organismos multilaterais como o Banco Mundial.

Estas questões tornam-se importantes para a pesquisa, sobretudo nos mestrados e doutorados, pois muita coisa ainda há para se investigar, sobremaneira no que se refere à Escola Ativa, dado que ainda não temos dados dos efeitos trazidos para a educação por esta estratégia metodológica direcionada especialmente às escolas do campo. Não sabemos, por exemplo, se há sucesso escolar dos seus alunos no que concerne a continuidade dos estudos no segundo ciclo do Ensino Fundamental, Ensino Médio e ensino superior, ou, se houver, quantos e em que medida esses egressos chegam e concluem a universidade.

Sobre a educação rural em seu conjunto, há ampla bibliografia: seja tratando da importância do currículo, da adequação do ano letivo à época de plantio e colheita, em contraposição ao ano civil adotado pelo Estado; seja a respeito das experiências localizadas de alfabetização e até mesmo das formas de compreensão de mundo, do trabalhador rural, com suas ideologias, crendices e dificuldades de se manterem na roça. Sobre as formas de conhecimento e educação do MST, também já se produziu muita coisa, mas sobre a Escola Ativa há poucos estudos.

É importante observar que essas pesquisas se direcionam prioritariamente para as propostas e práticas educativas elaboradas e em desenvolvimento no interior do MST e a seu respeito, desconsiderando as demais escolas que recebem trabalhadores rurais e moradores do campo, que vivem do trabalho no campo e que não são assentados de Reforma Agrária e nem fazem parte do movimento social, mas que engrossam a fileira dos trabalhadores explorados pelo capital.

\section{Do ruralismo pedagógico ao projeto de educação do MST}

Dadas as circunstâncias e considerando as condições objetivas de cada período, é necessário retomar a discussão sobre as propostas elaboradas e desenvolvidas no interior do movimento do "ruralismo pedagógico", apontando suas reminiscências no discurso dos atuais movimentos, mormente o MST. Essas propostas partem do princípio de que uma pedagogia eficiente para o homem do campo poderia contribuir para a sua fixação no meio rural, sem contudo levar em conta que o que realmente poderá prender o homem à terra são as condições econômicas e as políticas implementadas para o setor e não a pedagogia.

A pedagogia não pode ser responsabilizada pelo êxodo no setor rural, pois esta não tem a incumbência de fixar o homem nesse ou naquele meio. Se as condições econômicas não forem favoráveis à manutenção dos trabalhadores rurais na roça, não há Revista HISTEDBR On-line, Campinas, número especial, p.251-272, ago.2010 - ISSN: 1676-2584 257 
pedagogia que garanta sua permanência na área. Por ser as relações econômicas, como afirmado antes, que determinam em última instância, as formas de organização de um povo, somente estas relações, mediadas pela política, podem fazer com que o trabalhador rural passe a ter acesso à terra, aos equipamentos agrícolas e às condições de sobrevivência favoráveis que possam mantê-lo em sua atividade agrícola.

Partindo do princípio de que a História se desenvolve a partir de um movimento de rupturas e continuidades, é possível afirmar que muitas das propostas de educação elaboradas e, de certa forma, implementadas pelos educadores ruralistas, se fazem presentes ainda hoje, principalmente no interior do MST que, ao propor uma nova forma de educar a fração da classe trabalhadora que habita no campo, com conteúdos e metodologias específicos para o meio rural, faz a apologia de uma pedagogia que visa a fixação do homem no campo. De certa forma, está propondo as mesmas práticas já defendidas pelos autores que faziam a defesa do ruralismo pedagógico.

Algumas semelhanças entre as propostas do MST com as dos ruralistas aparecem na forma de ensinar e aprender de acordo com a realidade do homem do campo, cujo projeto funda-se na necessidade de fixação desse à terra como forma de viabilizar suas lutas e conquistas. Isso também é verdadeiro em relação à reforma agrária e a defesa da construção de uma identidade cultural do camponês, através da formação de valores ligados ao modo de vida dessa parcela populacional. Roseli Caldart, afirma que, nos últimos anos, o MST tem procurado dar ênfase à formação de valores, considerando que são essenciais, "exatamente aqueles que alimentam uma visão de mundo mais ampla ou histórica, e sustentam esta disposição de solidariedade e de espírito de sacrifício pelas causas do povo" (CALDART, 2000, p. 101).

Seguindo esse raciocínio de construção de uma nova forma de encarar o mundo, com uma nova cultura, a autora descreve algumas ações desempenhadas por assentados vinculados ao MST numa cidade do interior da Bahia e credita à prática um amplo caráter de formação política e responsabilidade social

Fazem parte da intencionalidade do MST neste campo as ações de solidariedade a trabalhadores em greve, assim como o estímulo para gestos como este narrado por Edith, professora de um assentamento na Bahia e aluna do Curso Magistério do MST: Na cidade onde eu moro, que é Itamaraju, no extremo sul da Bahia, acontece uma vez por semana o que o povo de lá começou a chamar de "o mutirão dos Sem Terra". É assim: a cada semana dois assentamentos são responsáveis pra fazer a limpeza da cidade. Os assentados passam o dia nas praças trabalhando, além de fazerem toda uma mística e cantarem o hino do MST. O almoço é conjunto, uma beleza. Eu já fui pra rua limpar e me senti muito bem... Da mesma forma, faz parte desta intencionalidade os sacrifícios e aprendizados dos milhares de Sem Terra em suas marchas rebeldes (CALDART, 2000, p. 101).

Essa passagem denota que o MST por si só é um movimento formador de cultura e que, através dele e da escola, poder-se-á transformar tanto a realidade do trabalhador rural como a da sociedade em geral, dado o seu alto grau de compromisso e de inserção na vida política, econômica e social do povo. Roseli Caldart afirma que, como um desdobramento da participação do trabalhador rural do MST na escola, emerge uma nova visão do que esta pode vir a ser e representar para as famílias de trabalhadores do campo.

A partir da compreensão que Caldart tem da relação dos movimentos sociais e do MST, em particular, com a sociedade como um todo, ela infere que 
se a escola pode vir ao seu encontro e não apenas o contrário, isto quer dizer também que ela pode passar a considerar sua realidade, sua cultura, suas necessidades de aprendizagem, fazendo delas a base do projeto pedagógico e político que desenvolve. Neste sentido, não é um dado inevitável que a escola represente a negação do mundo rural dos trabalhadores de sua cultura ou de uma coletividade em luta. Ao contrário, ela pode ajudar a enraizar as novas gerações na história e em um determinado projeto de futuro, à medida que as velhas gerações não deixem de se preocupar e de se ocupar com ela (CALDART, 2000, p. 196).

Se tomarmos os argumentos utilizados pelos educadores do MST e buscarmos compreender a realidade atual por esse prisma, poderemos perceber que discutir a educação rural na primeira metade do século XX ou, mais precisamente, os problemas apontados pelo ruralismo pedagógico é, antes de qualquer outra coisa, abordar um tema que, embora tenha sido amplamente debatido, ainda demanda grande interesse. Sendo o MST um dos principais movimentos de contestação da atual ordem econômica, que ainda vislumbra, em seus ideários, a possibilidade de construção de uma sociedade socialista, muitas de suas reivindicações assemelham-se àquelas cujas bases teóricas e pedagógicas são oriundas das propostas dos educadores ruralistas daquele período.

É preciso, por outro lado, entender que, com o passar do tempo, as necessidades da população se diversificaram e suas reivindicações também. Por isso, devemos compreender que o MST, embora traga no bojo de seu programa educativo, algumas reivindicações já almejadas por outros educadores, apresenta também algumas diferenças significativas em relação às propostas dos ruralistas; sobretudo no que diz respeito ao modelo de sociedade que se quer construir. O MST deseja a construção de um projeto socialista e essa possibilidade não passava pelo entendimento dos ruralistas, que defendiam uma proposta conservadora, nacionalista, capitalista.

O Movimento dos trabalhadores rurais sem-terra assim como os ruralistas, defende um programa educativo específico para o homem do campo, como uma de suas novidades na área educacional, entendendo-a como condição fundamental para a formação de um novo homem e de uma nova concepção de sociedade voltada para a solidariedade. Defende, também uma educação que tenha como fundamento último, a sociedade socialista, diferindo, assim, das propostas ruralistas do início do século $\mathrm{XX}$ que, por pretenderem uma educação inserida no modelo capitalista, não tinham no seu ideário a proposta de construção de uma sociedade igualitária a partir de uma revolução no campo.

Dentre os educadores que mais se sobressaíram na defesa de uma proposta ruralista voltada para a educação, merece destaque Sud Menucci, educador e ex-diretor da instrução pública no Estado de São Paulo e que muito se empenhou na defesa de uma escola voltada exclusivamente para os interesses do homem no meio rural. Ele defendia que, para tanto, deveríamos contar com professores formados para atender a essa clientela e a ela dar toda a assistência necessária para sua permanência no campo.

Assim como na primeira metade do século XX, há ainda hoje um grande questionamento em relação aos educadores que, formados no meio urbano, atuam no campo, pois, na compreensão dos defensores das propostas com teor ruralista, estes levam para aquele meio as ideologias de consumo e de mundo do homem citadino. Esse contraponto faz-se necessário, ao se verificar que, segundo Attad (1989, p. 27), "o homem rural não se identifica num sistema de valores homogêneo, apresentando simultaneamente valores em vias de desaparecimento do seu próprio meio e valores emergentes da vida 
urbano-industrial'. Para esse autor, essas diferenças de valores se intensificaram no Brasil, principalmente após o período de industrialização ocorrida a partir dos anos cinqüenta.

Para o Movimento Sem-Terra, a educação deve constituir-se num meio através do qual o trabalhador possa se fixar no campo. Pesquisadores, como Manuel Argumedo (1989, p. 28), no entanto, entendem que é 'urgente 'adecuar' esos programas a las características del medio rural, a la realidad de sus destinatarios, a las condiciones de la escuela rural; adaptarlos al mundo concreto del alumno, a su experiencia de vida y su trabajo", sem contudo se propor uma educação específica para o meio rural.

Além da discussão, em torno da especificidade na educação rural ou do campo, dos mecanismos de permanência nesse habitat, das condições que permitem o desenvolvimento da produção, é também necessário destacar a defesa do trabalho como fator educativo, feita tanto pelos ruralistas, como pelo MST, bem como a criação pelos primeiros, das escolas normais rurais. Estas se constituíram em importantes pólos de formação de professores para atuar no meio rural, assim como hoje, o MST tem investido nos cursos proporcionados pelo PRONERA ${ }^{3}$, voltados para a formação de professores.

A importância do ensino profissionalizante no meio rural, bem como suas relações com os trabalhos desenvolvidos pelo homem do campo, também ganharam evidência, assim como as dificuldades encontradas para a construção de um programa que, segundo os apologetas do ruralismo, deveria ser fundado no trabalho do educador, quer através das escolas rurais, quer através das escolas profissionalizantes voltadas para esse setor.

Tanto os ruralistas quanto os movimentos sociais concordam que existem grandes dificuldades para se formar um educador tipicamente rural ou do campo, visto que, para as escolas rurais, segundo os ruralistas, demandava-se a criação de escolas normais rurais. Porém, também nesse setor, havia a dificuldade de formar professores específicos, dado que não dispúnhamos de universidades que possibilitassem a formação de professores para a área; o que conduzia essa relação a um círculo vicioso: de um lado a falta de profissionais com formação específica para o trabalho de formação adequado ao homem do campo e, de outro, a falta de instituição que propiciasse a formação desses profissionais.

Sabemos que a luta pelo acesso à escola pública tem sido uma constante na história do Brasil, porém, essa luta tem sido mais árdua para aqueles que, por razões variadas, destinaram-se ao campo para trabalhar e viver. Isto tem justificado muitas das propostas que surgiram com vistas à eliminação do analfabetismo dos trabalhadores rurais, quase todas voltadas para a defesa de uma educação que, de alguma maneira, buscasse a fixação do trabalhador rural no campo.

Embora tenha havido uma enorme transformação no campo, as condições de trabalho do assalariado e do pequeno produtor não avançaram muito, sobretudo, no que diz respeito aos rendimentos, apesar de toda tecnologia disponível. Mesmo com a disponibilidade de energia elétrica e a telefonia rural, como instrumentos reivindicados pelos ruralistas, ainda na década de 1920, a grande maioria dos trabalhadores do campo ainda não conseguiu acesso a esses bens. Também é necessário considerar que o êxodo rural só tem aumentado nos últimos cem anos, inchando os grandes centros urbanos e ampliando a miséria daqueles que trabalhavam na roça e migraram para a cidade, em busca de uma vida mais confortável. Contribuíram, para esse êxodo rural, a falta de uma reforma agrária que levasse em conta os interesses dos trabalhadores e que possibilitasse a fixação do homem no campo a partir da conquista da terra, de forma que lhe possibilitasse tirar dela o seu sustento, bem como a implementação de políticas agrícolas que contribuíram com a concentração de capital nas mãos de uma pequena parcela de nossa elite política e econômica 
Apesar da distância no tempo e das lutas dos trabalhadores em geral, a educação praticada no campo não passou por mudanças profundas que induzissem a uma melhora nas condições do trabalhador rural, mormente no que diz respeito à utilização de equipamentos modernos para a lavoura. As políticas agrícolas adotadas pelos vários governos que passaram pela administração pública nos últimos cinqüienta anos, têm contribuído para dificultar tanto o acesso à terra, como a permanência de pequenos proprietários que dela tiravam seu sustento, tornando-se ainda, fator impeditivo para que os trabalhadores pudessem adquirir maquinários e implementos que pudessem ser utilizados como instrumentos de trabalho.

Neste sentido, falar de uma formação para o trabalho não tem outro significado, senão que o trabalhador é formado para o capital, numa clara constatação de que o trabalho neste caso não tem servido para educar, mas para embrutecer ainda mais o rude trabalhador que não tem acesso ao conhecimento produzido pela humanidade.

Mesmo com toda a luta com vistas à reestruturação do currículo escolar, este permanece da mesma forma, voltado para os alunos dos centros urbanos, inclusive com os seus conteúdos que tratam de temáticas referentes a esse meio. $\mathrm{O}$ ano escolar baseado no "ano civil" tem sido outra tônica da discussão, pois não leva em conta as necessidades do homem do campo, que necessita de mão de obra nos períodos de plantio e de colheita, dificultando, dessa maneira, a permanência da criança na escola, apesar da LDB 9394/96, no artigo vinte e três, parágrafo segundo, garantir a adequação do calendário escolar ao ciclo agrícola.

Para amenizar este problema, tem-se investido nos cursos que utilizam a metodologia da alternância, que propicia ao aluno um tempo de estudo no ambiente escolar (tempo escola) e outro período de estudo na comunidade em que reside (tempo comunidade), favorecendo que o aluno possa se dedicar também ao trabalho produtivo.

Embora ainda haja uma discussão sobre a necessidade de se investigar se é recomendável ou mesmo desejável que tenhamos uma escola voltada exclusivamente para o homem do meio rural, dada a abrangência do conhecimento hoje disponível na sociedade, não se pode desconhecer que os movimentos sociais defendem que o saber historicamente construído por toda a sociedade deve estar acessível a todos os povos, embora, ao mesmo tempo, exista um saber específico que poderá auxiliar no desenvolvimento de algumas práticas, que poderiam beneficiar aqueles setores sociais que a eles se dedicam, tanto no plano econômico como em qualquer outro setor social.

O MST tem trabalhado também para desenvolver a questão educativa visando à eliminação do analfabetismo existente tanto em seus quadros quanto na sociedade em geral, além de afirmar que é de fundamental importância que os filhos dos agricultores permaneçam no campo, que dêem continuidade à luta pelo acesso a terra, partilhando as tradições e o projeto social do movimento. Em outras palavras, os dirigentes desse movimento consideram que a luta por uma reforma agrária e por uma sociedade socialista não deve parar jamais, pois somente assim se construirá o homem novo, o homem socialista almejado pelo movimento. A educação é, nesta perspectiva, compreendida como sendo fundamental nesse processo.

A luta para que o trabalhador rural permaneça no campo, mais do que um problema pedagógico, deve ser compreendida como um problema econômico, pois há grandes dificuldades de permanência na roça para aqueles que não têm terra suficiente para produzir de acordo com as necessidades do mercado, mesmo que ainda existam aqueles que insistam em se manter como meeiros, arrendatários ou parceiros, praticamente inviabilizados pelas condições de vida oferecidas naquele ambiente. 
Devemos considerar ainda que um dos maiores problemas do país, na primeira metade do século XX, segundo a ótica dos defensores do ruralismo pedagógico, era o de que o homem rural tinha uma cultura própria, com necessidades específicas, devendo portanto, requerer soluções apropriadas, iniciando essa formação pela alfabetização, pois suas necessidades eram vistas como sendo diferentes das necessidades do homem de vida urbana, sendo muitas vezes compreendidas até mesmo como antagônicas.

Essa mesma opinião era compartilhada por Ruth Ivoty Torres da Silva, que afirmava, em seu texto sobre educação na zona rural, que:

\begin{abstract}
No campo conservam-se formas tradicionais de vida em comunidade, há muito desaparecidas na cidade [dado que] a família rural ainda mantém a forma de vida de trabalho, sob a autoridade do chefe, num verdadeiro regime patriarcal. A identidade de interesses e aspirações (boa colheita, bom tempo, etc.) e as amizades levam à união de famílias vizinhas, principalmente em tarefas que, temporariamente, requerem maior número de braços (SILVA, 1970, p. 13).
\end{abstract}

Além desses aspectos comuns aos trabalhadores rurais, as próprias dimensões políticas e religiosas do roceiro eram vistas como sendo diferentes das dimensões políticoreligiosas do homem urbano, sendo o primeiro, via de regra, em termos morais e políticos, considerado muito mais conservador que este último.

Ruth Ivoty Torres da Silva corrobora o pensamento de Menucci, no que diz respeito ao papel do Estado em suas ações na zona rural. Para ambos, os governantes têm sistematicamente abandonado as áreas interioranas e concentrado seus investimentos nos meios urbanos, lugar de maior concentração de pessoas e, portanto, com maior potencial de voto nos momentos de eleições. Daí Silva afirmar que "o homem rural manifesta desconfiança para com o Estado, vendo nas leis encargos e não benefícios. Em relação à escola revela incompreensão das vantagens da educação, pelo afastamento dos filhos, assim que os pode utilizar no trabalho, prejudicando sua freqüência regular e sua permanência na mesma" (SILVA, 1970, p. 13).

Essas práticas dos órgãos públicos, via de regra eram condenadas pelos defensores do ruralismo pedagógico. Em um de seus discursos, pronunciado na cidade de Salvador/BA, Sud Menucci, (1946, p. 8), ao fazer sua saudação ao sertanejo, chamava a atenção para a existência de um Brasil ainda desconhecido, o Brasil do sertanejo, afirmando reconhecer a existência desse outro Brasil que a costa fazia questão de ignorar. Naquele discurso, ele afirmava que o Brasil de verdade localizava-se naquela área, enquanto que o Brasil do lado de cá não passava do "Brasil da mentira, o Brasil da caricatura, o Brasil da contrafação, o Brasil que não está em harmonia com os anseios, com os desejos, com as aspirações da grande massa de seu povo". Alegava ainda que aquela gente do sertão e da floresta era a única que possuía o espírito da terra, "a única que, em a dominando, soube criar dentro do habitat brasileiro, uma civilização atrasada, inegavelmente, retardária, sem dúvida, primitiva, por certo, mas original e forte, inteiriça e integral como todas as cousas simples e sinceras que se inspiram honestamente $e$ galhardamente no ambiente das realidades nacionais" (MENUCCI, 1946, p. 8).

Essas questões se colocam porque os ruralistas defendiam, e os movimentos sociais atuais continuam a defender que a educação deve ser realizada como política pública, quando esta deveria ser tratada como política de Estado, não ficando a mercê da vontade dos governantes de plantão. Enquanto a educação popular continuar a ser tratada como política de governo, a educação do trabalhador em geral e a educação do trabalhador rural em particular jamais poderão trazer os frutos esperados pelos movimentos sociais, 
pois a escola continuará a ser colocada a serviço dos interesses das camadas dominantes na sociedade.

A luta pela educação e pela reforma agrária implementada pelo ruralismo e pelo MST em muito se assemelha, embora em ambos os casos não se tenham sido amparadas pelas políticas governamentais, o que nos permite enfatizar que, embora a luta dos trabalhadores seja feita de avanços e retrocessos, a luta pela educação rural não tem conseguido avançar a ponto de possibilitar aos trabalhadores rurais uma pedagogia autônoma como querem suas lideranças políticas e intelectuais.

Assim, não basta defender a integração do homem com a natureza através da formação integrada do trabalho intelectual com o trabalho braçal, como quer o Movimento, visto que são as condições materiais que criarão as condições de sobrevivência dos trabalhadores no campo ou na cidade. Portanto, ao se propor uma nova forma de ensinar e aprender de acordo com a realidade do homem do campo, visando à fixação desse à terra como forma de viabilizar suas lutas pela reforma agrária, o MST, como faziam os defensores do ruralismo pedagógico, deixa de considerar que as bases materiais de determinadas sociedades determinam em última instância as formas de pensar e de agir de seu povo.

Evidencia-se, portanto, que as condições objetivas de fixação do trabalhador rural no campo dependem de medidas econômicas que possibilitem a sua permanência na roça e não das pedagogias impostas em determinados momentos ou dos esforços despendidos por meio de educação, dado que como vimos, na parte inicial deste trabalho, a partir das exposições de Marx, que são as condições reais de sobrevivência, ligadas à maneira como os trabalhadores se organizam, para reproduzirem sua existência, que determinam suas formas de vida e não as ideias produzidas pelos homens em ou sobre um dado habitat.

Mesmo sendo considerado como um dos movimentos mais importantes do Brasil a partir do último quarto do século XX, o MST em que pese reivindicar um caráter revolucionário, acaba assumindo posturas conservadoras, ao atribuir à educação uma função redentora dos males vividos por nossa sociedade. Seus dirigentes colocam num mesmo patamar a necessidade de se fazer a reforma agrária e o investimento na educação. Para o MST, a conquista da terra de nada adiantará se não vier acompanhada de uma educação voltada para os interesses dos trabalhadores em geral e dos trabalhadores rurais em particular.

Os projetos de educação do campo não levam em consideração a categoria totalidade, uma vez que não fazem a relação das formas atuais de produção da vida sob o capital com a necessidade de formação que propõem. Segundo Oliveira (2008), a necessidade de uma educação do campo, já pressupõe uma divisão fenomênica entre o rural e o urbano, como se ambos existissem separadamente.

Nesse caso, ao desconsiderar a categoria "totalidade", não conseguem pensar a realidade como objetiva e, assim, não trabalham com a ideia da necessidade dos projetos tomarem o conhecimento objetivo, científico, mas apenas com o "saber dos agricultores" (OLIVEIRA, 2008), fazendo com que os defensores da escola "do campo", não percebam que num momento de crise do sistema capitalista, em que se tem que negar a possibilidade do entendimento da realidade objetiva, negue-se também as categorias de historicidade e contradição, tão caras ao materialismo histórico.

Como os projetos de educação do campo não consideram a categoria contradição, quando tomada como a relação entre contrários que se excluem e se determinam, vêem somente vantagens num modelo que apresenta sua lógica pautada numa agricultura familiar ou camponesa, como no caso do MST.

Sendo assim, no entender de Oliveira (2008), 
Os projetos de educação do campo por não trabalharem com as categorias totalidade, historicidade e contradição também não levam em consideração a categoria mediação. Tal atitude deve ser compreendida dentro da perspectiva fenomênica em que tentam captar a realidade, atitude esta que considera não haver diferença entre essência e aparência, uma vez que os fatos se bastam em seus aspectos fenomênicos, ou seja, busca analisar o real em sua mera aparência.

Outro aspecto importante para a compreensão da escola do campo é o conceito de práxis, uma categoria importante para o entendimento das epistemologias dos projetos de educação do campo. Para o marxismo, mais que interpretar a realidade, interessa transformá-la, o que coloca a prática, como o início da ciência social. Para alterá-la, entretanto, é necessário entendê-la. Neste sentido, o entendimento da realidade não pode ser feito sem a mediação de conhecimentos teóricos, entendidos estes enquanto abstrações realizadas a partir de constantes e infinitas aproximações entre a realidade empírica e o conjunto de conhecimentos sobre a realidade, produzidas pela humanidade, por um ramo da ciência e/ou por um pesquisador em especial (Oliveira, 2008).

No entanto, por não considerar a teoria como parte imprescindível da formação do concreto pensado, supervalorizando a prática, tomada em seu aspecto fenomênico, individual e utilitarista, os projetos de educação do campo caem num pragmatismo exacerbado aproximando-se ainda mais das tendências pós-modernas.

Outra deformação da formação fenomênica encampada pelo MST e os defensores da educação do campo, advém da não consideração da categoria totalidade, muitas vezes substituída pela categoria holismo, nos termos da "categoria da complexidade", de Edgar Morin (MORIN, 2000).

Ainda segundo Oliveira (2008), negando a possibilidade do conhecimento objetivo e afirmando a possibilidade somente de representações, cai-se no culturalismo subjetivista; negando a realidade como um todo estruturado - a totalidade, e defendendo a singularidade, cai nos particularismos e, por fim, negando a possibilidade da historicidade e defendendo a imediatez dos fenômenos sociais, cai no presentismo, que leva ao pragmatismo. A burguesia se utiliza deste conjunto de ideários para justificar o irracionalismo e, assim, negar a possibilidade do conhecer objetivamente, bem como de se organizar para superar seu sistema. O "Movimento por uma Educação do Campo" apresenta características que permitem dizer que de certa forma, se aproxima destes ideários.

O pragmatismo, se orienta pela ênfase às consequiências do que seja a realidade: sua utilidade para determinada pessoa e/ou grupo, dado que o que importa não é buscar as explicações da realidade, mas como viver melhor, encaminhando as situações vividas por um indivíduo, um grupo e/ou mesmo uma sociedade. Assim, não há a necessidade do ser humano entender objetivamente a realidade, mas fazer opções de como interpretá-la segundo seus interesses, o que faz do pragmatismo um relativismo filosófico.

Sendo assim, o critério de verdade para o pragmatismo é aquilo que é útil para o encaminhamento de uma determinada situação. Para essa corrente filosófica, é interessante ver a utilidade do que se imagina como realidade, importa uma prática. Esta prática é a prática individual que, limitada ao cotidiano, se vê desligada da teoria.

Toda a pedagogia do Movimento dos Trabalhadores Rurais Sem Terra, tem por base a pedagogia de Paulo Freire, neste sentido, é Roseli Caldart, quem afirma que existe uma relação entre a Pedagogia do Movimento e a Pedagogia do Oprimido (teorizada por Paulo Freire), dado que segundo ela, ambas são materializações históricas da Pedagogia da 
Práxis e por isso, a Pedagogia do Movimento também é herdeira da Pedagogia do Oprimido.

Para Caldart,

a Pedagogia do Oprimido traz para a reflexão pedagógica o potencial formador da condição de opressão, que exige a atitude de busca de liberdade e de luta contra a opressão, e que coloca os oprimidos na condição potencial de sujeitos da sua própria libertação. A Pedagogia do Movimento continua esta reflexão e chama a atenção para a dimensão humanizadora/formadora da radicialização desta busca pela libertação que acontece de forma coletiva através da luta social: as pessoas se educam/se humanizam/se libertam participando de Movimentos Sociais cuja dinâmica combina luta social, de perspectiva histórica, e organização coletiva CALDART (s/d., p. 7-8).

Segundo Oliveira (2008, p. 392), a partir desta concepção, há uma supervalorização do ensinamento de saberes populares, sem que se coloque a mesma importância para o ensino de conhecimentos científicos. Este ideário parte do pressuposto existencialista de que o mundo é o sentido que cada indivíduo dá a ele, sendo, portanto, função da escola "comunicar os saberes" que cada indivíduo tem deste.

Sendo assim, passa a se valorizar todo e qualquer tipo de saber construído, ou melhor, consensuado por seus interlocutores, dado que por não existir uma verdade objetiva, tudo passa a ser aceito como verdadeiro, desde que haja consenso entre os atores. Assim, passa a ser tidos como verdades conhecimentos, habilidades, sentimentos, valores, modo de ser e de produzir, de se relacionar com a terra e formas de compartilhar a vida.

A defesa desta proposta de educação que se constrói a partir da realidade, segundo o MST, se dá porque "a gente foi vendo que queria era uma proposta de educação que não trouxesse as coisas prontas para a criança, e sim que ela construísse a sua própria educação, e que fosse participativa para a escola e os pais" (MST, 2005, p. 17).

A pedagogia tida como ideal para o MST, como vimos é aquela derivada da pedagogia do oprimido de Paulo Freire. A base desta pedagogia é o existencialismo cristão, sendo que para o existencialista, a existência humana precede a qualquer essência. Por isto, podemos dizer que para o existencialismo, o homem se faz no mundo, ao longo de sua vida, através de suas experiências, seus conflitos, suas conquistas e derrotas, não existindo uma essência do que seja o ser humano. Assim cada indivíduo é um ser particular, que constrói sua própria essência. Para o existencialismo, segundo Huisman, (2001, p. 104), "só o homem dá um sentido ao objeto".

Este pensamento é importante para se entender as matrizes do pensamento social na atualidade, inclusive dos movimentos sociais e dos projetos de educação do campo, dado que o existencialismo tem muito de relativista e de irracionalista, já que para o existencialista a verdade depende de um conjunto de escolhas individuais, e do sentido que os indivíduos dão às coisas, o que torna impossível qualquer tipo de conhecimento objetivo. $\mathrm{O}$ existencialismo serve também de justificativa para o capitalismo dada a relação entre o que é o mundo e o indivíduo. Para esta corrente, são escolhas feitas pelos indivíduos que permitem à burguesia ligar a ideia de liberdade com liberdade de escolha, ideia tão cara à burguesia para a manutenção de seu sistema.

Como a realidade é contraditória, histórica e dialética e não apenas uma questão de escolhas de um cientista e/ou de um filósofo, necessitamos de um método para entendêla. Como a realidade é material, entendemos que o melhor método para o seu entendimento 
é o materialismo histórico e dialético, que vê a realidade como materialista histórica e dialética, buscando entendê-la em toda sua totalidade e complexidade.

Partindo de uma perspectiva marxista, é preciso afirmar que para Marx o ponto de partida do entendimento da coisa em si é a realidade tomada empiricamente mas que, através de análises sucessivas, tornadas possíveis por um método de investigação específico, permite ao homem ascender à categoria do concreto pensado, ou seja, do real efetivamente existente, que é a realidade como síntese de múltiplas relações - a coisa entendida em sua totalidade e historicidade.

O marxismo se diferencia do existencialismo, por entender que a realidade existe independentemente da consciência sobre ela, dado que o homem tem uma essência, que é sua capacidade de transformar o mundo e criar, em última instância, seu próprio mundo. Já para o existencialista a realidade deriva da consciência sobre o mundo, a ponto de os filósofos existencialistas afirmarem que a "existência precede a essência".

Ao contrário do que tem afirmado, tanto o MST como alguns formuladores da proposta de educação do campo, a verdade para o marxismo não está numa teoria, mas numa teoria que corresponda à realidade histórica de uma época, única forma de ser útil para a intervenção na realidade.

O que se tem observado, no entanto, é que os "pós-estruturalistas" buscam estabelecer uma mudança de eixo, um "salto" da realidade para a linguagem como agente constitutivo da consciência humana e da produção social do sentido. Por se visar a produção dos sentidos adere-se a uma suposta sedução da "virada linguística", levada agora a extremos pela suposição de que há uma anterioridade da linguagem em relação ao mundo real e assim, o que se pode experimentar como "realidade" nada mais seria do que um construto ou "efeito" do sistema particular de linguagem ao qual pertencemos.

Sendo assim, atribui-se um peso exagerado à linguagem, acreditando-se que é pela linguagem que se domina e que também seria por ela que se alcançaria a libertação. Assim ao se cumprimentar o público, há a necessidade de se referir a todos os homens e todas as mulheres, da mesma forma, fala-se aos professores e professoras e aos educandos e educandas, quase sempre dando uma predileção para o feminino. Nesse caso, há um deslocamento dos conflitos, das relações de classe para a linguagem, e para as questões de gênero, entendendo-se que mudando a linguagem, mudar-se-á o real.

Outra característica dos movimentos sociais do campo, sobretudo do MST é sua ligação com a igreja, aliás, esse movimento foi fundado no interior da Comissão Pastoral da Terra, dentro do que podemos definir como "comunitarismo cristão".

Como os movimentos sociais têm aderido à fenomenologia, adotada pelo existencialismo cristão, a tentativa do homem de entender a realidade, deixando de lado os princípios científicos elaborados pela humanidade leva ao que Kosik (2002) denominou de pseudo-concreticidade, ou seja, a procura do entendimento da realidade, com base na cotidianidade e na experiência empírica, reduz os fatos a seu aspecto fenomênico, não significando o seu real entendimento.

Os movimentos sociais que defendem um projeto de educação para o campo, acreditam que com uma educação adequada ao meio rural, o êxodo rural poderia ser solucionado, pois o grande objetivo desses movimentos, sempre foi melhorar as condições de vida da comunidade. Estes movimentos, dentre eles o MST, dizem acreditar que a crise por que passa o meio rural provêm de uma educação voltada para o meio urbano. Para resolver estes problemas, portanto, haveria a necessidade de uma nova educação que levasse em consideração a realidade do campo.

Para viabilizar a formação do homem do campo, procurou-se adotar uma metodologia denominada de Pedagogia da Alternância, que chegou ao Brasil na década de 
1960, através das Casas Familiares Rurais implantadas através da pastoral social das igrejas, sobretudo as Comunidades Eclesiais de Base - CEB's" (BEGNAMI 2002, p. 110).

Outra característica deste basismo dos movimentos sociais refere-se ao descentramento da política, marcadas pelo suposto desaparecimento das classes sociais e das lutas em escala macro ao mesmo tempo que dá espaço ao surgimento de atores microsituados e mais interessados em lutas por interesses localistas e imediatos, fugidios e refratários às lutas em escala maiores, típicas de um pensamento anti-marxista.

Nesta concepção, tiveram importância o pensamento de Habermas (2000), Touraine (1984) e de Foucault (1977 e 2000). Para Habermas (2000) o trabalho poderia ser entendido como elemento formador do homem, portanto possuidor de um caráter ontológico, somente nas sociedades que não tinham passado pela modernidade. Segundo este autor, na sociedade atual, de complexas relações, o elemento formador do humano não mais seria o trabalho, mas, a comunicação. Assim, o ser humano não seria mais formado a partir de sua relação metabólica entre homem-natureza, mas a partir das diferentes formas com que os indivíduos veriam esta relação, que seria então comunicada através da linguagem.

O MST tem uma pedagogia que é o jeito através do qual vem formando o sujeito social de nome "Sem Terra", e que no dia a dia educa as pessoas que dele fazem parte. Esta é a "Pedagogia do Movimento Sem Terra", cujo sujeito educador é o próprio Movimento, não apenas quanto ao trabalho no campo específico da educação, mas também e principalmente quando sua dinâmica de luta e de organização intenciona um projeto de formação humana, que começa com o enraizamento dos sem terra em uma coletividade, que não nega o seu passado e projeta um futuro que eles mesmos poderão ajudar a construir. Ou seja, o MST não aceita uma pedagogia que não seja aquela derivada de suas ações práticas de educação e uma suposta formação humana geral, que são pensadas para formar seu sujeito coletivo, um sujeito sem terra (CALDART, s/d., p. 6).

Para o Movimento sem terra, nenhuma corrente pedagógica dá conta de refletir sobre sua prática, de ter um conteúdo que reflita sobre a práxis pedagógica do MST, buscando um sentido de movimento pedagógico, de práticas que exigiram uma elaboração teórica que por sua vez exigem um salto de qualidade em novas práticas (CALDART, s/d., p. 5). Neste sentido, a Pedagogia do Movimento é a mistura de várias teorias pedagógicas que, pretendem misturar correntes filosóficas, entre elas o marxismo e o idealismo existencialista, numa base eclética, utilizada como método de formação.

Nesse momento, aparece um problema na relação entre teoria e prática, uma vez que como demonstrou Pistrak (2006), sem teoria revolucionária, não há prática revolucionária. Portanto, trabalhar a educação com base numa realidade alienada e superficialmente observada, é a forma mais fácil de fugir de uma prática que altere a realidade, mesmo que esta seja unicamente a de conseguir uma melhor inserção na sociedade capitalista e não a superação desta sociedade.

Como não há uma teoria revolucionária, não há uma prática revolucionária, pois ao não se buscar a superação da sociedade capitalista, procura-se sua adaptação a ela. Nesse caso, parte-se do pressuposto de que acabou a luta de classes, uma vez que se entende que acabaram os antagonismos entre as classes sociais, ou melhor, o problema agora passa a ser de diferença e não mais de desigualdade, pois analisa-se a realidade a partir das "diferenças" culturais e não das lutas de classes.

Outro aspecto considerado fundamental, tanto pelos movimentos sociais que atuam no campo, como os formuladores das propostas de educação do campo é o trabalho como princípio educativo, que tem servido para orientar o desenvolvimento do programa, 
de modo a resgatar os valores do trabalho coletivo contribuindo para a autonomia e o empoderamento dos jovens agricultores familiares (BRASIL, 2005, p. 24).

O problema é que nem sempre o trabalho assume a perspectiva da formação para a superação das relações de classe, pois é visto como uma forma de melhorar a vida dos trabalhadores que atuam no campo, sem questionar as relações desiguais produzidas no sistema capitalista. Isto aparece muito claramente no documento do MST, quando se afirma que

queremos que a escola ajude as crianças a entender como funciona o mundo do trabalho. Que consigam comparar o trabalho de seus pais e companheiros com o trabalho de outros trabalhadores do campo e da cidade. Que conheçam o funcionamento de uma granja, de uma fábrica, de um mercado, que saibam a complexidade do processo produtivo (...) que entendam a importância do trabalho na sociedade tendo uma experiência concreta de trabalho útil na escola e no próprio assentamento (MST, 2005, p. 72).

Nesse sentido, distancia-se da categoria de totalidade, tal como a vemos em Marx e na literatura marxiana em geral, enquanto se aproxima da teoria da complexidade desenvolvida por Edgar Morin, sendo que de acordo com Oliveira através da categoria totalidade, de origem marxiana, podemos perceber que o real é um todo estruturado, composto por múltiplos fenômenos, mas que mantêm relações entre si que e que permitem o conhecimento do todo (OLIVEIRA, 2008, p. 406).

Apesar de ser um dos proponentes das propostas de educação do campo, seguindo a lógica das teorias utilizadas neste século, no Brasil, é importante notar que o MST não define sua proposta pedagógica nos marcos de nenhum modelo pedagógico tradicional. Ao contrário, procura conjugar várias posturas, unindo a atuação de existencialistas cristãos como Paulo Freire, construtivistas como Piaget e marxistas como Makarenko, passando ainda por propostas nacionalistas, como as de Jose Marti.

É graças a estas conjunções de pensamentos, de autores tão díspares que podemos afirmar que o projeto pedagógico do Movimento dos Trabalhadores Rurais Sem Terra é eclético, além de possuir uma função redentora da miséria a que a maior parte da sociedade brasileira está submetida.

Ao acreditar na educação como fator de redenção, Caldart, afirma que deseja uma educação de classe voltada para os interesses dos trabalhadores rurais sem terra, alegando ainda que "se nós não tivermos acesso ao conhecimento, se nós não democratizarmos a educação, nós não conseguiremos construir uma sociedade mais justa e igualitária" (CALDART, 1997, p. 26).

A partir desta discussão, compreende-se também que os problemas da educação no Brasil não se restringem ao meio rural, nem os problemas da educação rural se restringem à falta de escolas ou de propostas para esse setor. Para o MST e alguns pedagogos que trabalham na perspectiva de uma educação diferenciada, englobam também os professores que trabalham nesse meio, pois estes são preparados para atuar no meio urbano, com material típico do setor urbano. Segundo Haddad (1994, p.16), há falhas de formação nesse sentido, visto que "não há uma proposta de formação específica para o professor da zona rural", que leve em conta as especificidades desse meio e o conhecimento que a criança traz em sua bagagem.

Cumpre assinalar que a proposta pedagógica do MST não é uma proposta que surge do nada, ou que busque dar início a uma nova pedagogia. $\mathrm{Na}$ prática, é uma apropriação da proposta educacional de Paulo Freire, inclusive com os problemas 
decorrentes dessa metodologia, acompanhada das orientações pedagógicas de pensadores como Makarenko, Piaget, Marti e Che Guevara.

Ao pensar o mundo de forma fenomênica o MST parece não enxergar as contradições do capital propondo uma ação que pode significar, ao invés da superação da sociedade capitalista, o represamento destas possibilidades. Sendo assim, a educação do campo torna-se, no sentido dado por Saviani (2007), também um novo tecnicismo, adequado ao momento atual do capitalismo.

Por outro lado, caberia perguntar: até que ponto uma pedagogia específica para o meio rural constituiria em avanço para o setor? Faz-se necessário indagar também, se mais importante não seria que toda a sociedade tivesse acesso a todas as informações que lhes interessassem, e se todas as tecnologias não deveriam estar disponíveis a todos os ramos de produção. Nesse caso, a luta por uma educação ruralista não seria mais um retrocesso na defesa da educação do homem do campo? Creio que estas questões poderão ser discutidas em trabalhos futuros.

É necessário ainda, atentar que sem a utilização adequada do método, o processo de construção de cursos de educação específica para o campo não resolverá o problema da formação, pois há sempre o perigo de se perder em questões menores, como problemas de gênero, étnicos ou ficar na contradição entre campo e cidade e, perder de vista que a sociedade somente se transformará a partir do momento que se entender que é no processo de luta de classes que se forma o sujeito para atuar e lutar para transformar sociedade, almejando assim, a utopia da sociedade igualitária.

A discussão a respeito da educação proposta pelo ruralismo pedagógico, bem como a praticada pelos Trabalhadores Rurais Sem-terra, sobretudo este último por estar em movimento, não se esgotará aqui, mas possibilitará que outros trabalhos possam avançar nessas pesquisas. O que não se pode perder de vista é a atualidade do materialismo histórico e dialético para a compreensão da realidade atual e, assim pensar em um mundo que possa ser compreendido pelo homem, tendo claro que é a dinâmica da realidade que fará com que tudo o que ora se está estudando e fazendo venha a se transformar, pois como dizia Lenine, "tudo que é sólido se desmancha no ar".

\section{REFERÊNCIAS BIBLIOGRÁFICAS}

ARGUMEDO, M. Educacion y Desarrollo Rural, Sembrando Ideas. reflexiones para la educacion rural, Universidade Católica de Chile, Santiago: 1989.

ATTAD, J. J. O mundo da escola rural nas representações sociais de seus egressos. Campinas: Dissertação FE/Unicamp, 1989.

BEZERRA NETO, Luiz. E COLARES, Anselmo Alencar. Contribuição ao debate acerca da utilização do materialismo histórico e dialético como referencial teórico na pesquisa histórico-educacional. In: WWW.histedbr.fae.unicamp.br, 2002.

BEZERRA NETO, Luiz. Sem-terra Aprende e Ensina: Estudo sobre as práticas educativas do Movimento dos Trabalhadores Rurais, Campinas: autores associados, 1999.

Brasil, MDA/SDT. 2005

CALDART, R. S. O MST e a formação dos sem terra: o movimento social como princípio educativo. São Paulo: Estudos Avançados, 2001. 
CALDART, R. S. Pedagogia do movimento Sem Terra. São Paulo: Expressão Popular, 2004.

CALDART, R. S. Pedagogia do Movimento Sem-terra, Petrópolis: Vozes, 2000.

CALDART, Roseli Salete. Educação em Movimento: Formação de educadoras e educadores no MST. Petrópolis: Editora Vozes, 1997.

CALDART, Roseli Salete. Formação de Educadores/as no MST - Um currículo em movimento - mimeog, 1997.

CNBB. Texto base da Campanha da Fraternidade. 1998.

FOUCAULT, M. Arqueologia das Ciências e História dos Sistemas. Rio de Janeiro: Editora Forense Universitária, 2000.

FOUCAULT, M. Vigiar e punir. Petrópolis, RJ: Vozes, 1977.

FREIRE, P. Educação como prática da liberdade. Rio de Janeiro: Paz e Terra, 2006.

FREIRE, P. Pedagogia do Oprimido. Rio de Janeiro: Paz e Terra, 2005.

FREIRE, Paulo. Ação Cultural para a Liberdade e outros escritos. Rio de Janeiro: Editora Paz e Terra, 1984.

FUNDEP, Coragem de Educar. uma proposta de educação para o meio rural. Petrópolis: Vozes, 1995.

GUIMARÃES, J. R. O cristianismo e a formação da moderna questão agrária brasileira. In: PAULA, D. G. de, STARLING, H. M. M., GUIMARÃES, J. R. (Orgs.). Sentimento de Reforma Agrária, Sentimento de República. Belo Horizonte: UFMG Editora, 2006.

HABERMAS, J. O discurso filosófico da modernidade. São Paulo: Martins Fontes, 2000.

HADDAD, Sérgio; e DI PIERRO, Maria Clara. A educação no Movimento dos Trabalhadores Rurais sem Terra em Bagé e Sarandi. (RS) Brasília. D.F: INEP, 1994.

HUISMAN, D. História do existencialismo. Bauru, SP: EDUSC, 2001.

Jornal Sem Terra, Maio de 1993

KAUTSKY, K. A questão agrária. Coleção Proposta Universitária. São Paulo: Proposta Editorial, 1980.

KOSIK, K. Dialética do concreto. 7. ed. São Paulo: Paz \& Terra, 2002.

KOSIK, Karel. Dialética do concreto. Tradução Célia Neves e Alderico Toribio. Rio de Janeiro: Paz e Terra, 1976.

LEÃO, Antônio Carneiro. Sociedade rural: seus problemas e sua educação. Rio de Janeiro: s/d. 
LEFEBVRE, Henri. Lógica formal e lógica dialética. 2 ed. Tradução Carlos Nelson Coutinho. Rio de Janeiro: Civilização Brasileira, 1979. (Coleção perspectivas do homem, v. 100).

LÊNIN, V. I. Capitalismo e agricultura nos Estados Unidos: novos dados sobre as leis de desenvolvimento do capitalismo na agricultura. São Paulo: Editora Brasil Debates, 1980.

LÊNIN, V. I. Materialismo e Empiriocriticismo: notas críticas sobre uma filosofia reacionária. Moscou: Edições Progresso; Lisboa: Editorial Avante, 1982.

LOURO, Guacira Lopes. A história oral e a pesquisa sobre gênero. In: Série Documental Eventos, n. ${ }^{\circ}$ 5, maio de 1994, MEC - INEP.

LOWY, M. As esquerdas na ditadura militar: o cristianismo da libertação. In: REIS FILHO, D. A. e FERREIRA, J. (Orgs.). As esquerdas no Brasil. 2. v. Nacionalismo e reformismo radical, 1945-1964. Rio de Janeiro: Civilização Brasileira, 2007.

LOWY, Michael. As aventuras de Karl Marx contra o Barão de Münchhausen: marxismo e positivismo na sociologia do conhecimento. Tradução Juarez Guimarães e Suzanne Felice Léwy. São Paulo: Busca Vida, 1987.

MAKARENKO. A S. Conferências sobre Educação Infantil. São Paulo: Editora Moraes, 1981.

MAKARENKO. A S. Poema Pedagógico. São Paulo: Editora brasiliense, 1985.

MARX, K, Manuscritos econômicos e filosóficos. São Paulo: Nova Cultural, 1987.

MARX, Karl. ENGELS, Friedrich. A ideologia alemã. Rio de Janeiro: civilização brasileira, 2007.

MARX, Karl. ENGELS, Friedrich. Manifesto do Partido Comunista. In: Obras escolhidas. Lisboa: Edições Avante, 1982.

MENUCCI, S. A Ruralização, Imprensa Oficial do Estado de São Paulo: 1944.

MENUCCI, S. Discursos e conferências ruralistas. São Paulo: 1946.

MENUCCI, S. Pelo sentido ruralista da civilização: subsídios para a historia do ensino rural no estado de São Paulo (1892-1935) São Paulo: Revista dos Tribunais 1935.

MOLINA, M. C. A constitucionalidade e a justicialidade do direito à educação dos povos do campo. In: SANTOS, C. A. dos. Educação do Campo, Políticas Públicas, Educação. Brasília: INCRA/MDA/NEAD, 2008.

MOLINA, M. C. Educação do campo e pesquisa: questões para reflexão. In: MOLINA, M. (Org.). Educação do campo e pesquisa: questões para reflexão. Brasília: Ministério do Desenvolvimento Agrário, 2006.

MORIN, E. Complexidade e transdisciplinaridade: a reforma da universidade e do ensino fundamental. Natal: EDUFRN, 2000. 
MORIN, E. Introdução ao pensamento complexo. 3. ed. Lisboa: Instituto Piaget, 2001.

MST. Dossiê MST ESCOLA: documentos e estudos, 1990-2001. São Paulo: Editora Expressão Popular, Setor de Educação do MST/Iterra, 2005.

NETTO, José Paulo. Relendo a teoria marxista da história. In: SAVIANI, Dermeval. LOMBARDI, José Claudinei. SANFELICE, José Luis. História e história da Educação: o debate teórico-metodológico atual. Campinas: Autores Associados, 1998. (p. 50-64).

O MST e a Educação<URL:http://www.sanet.com.br semterra/mst-3htm> [14 jul 1997]

OLIVEIRA, M. A. de. As bases filosóficas e epistemológicas de alguns projetos de educação do campo: do pretendido marxismo à aproximação ao ecletismo pós-moderno. Curitiba, UFPR, setor de educação, Tese, 2008.

PIAGET, J. Psicologia e Pedagogia. Rio de Janeiro: Editora forense, 1970.

PISTRAK, Fundamentos da escola do trabalho. São Paulo, expressão popular. 2006 Revista Sem Terra, ano 1 n. 1 jul./set. 97

Revista Sem Terra, ano 1 n. 2 out./dez. 97

RIZZOLI A. O real e o imaginário na educação rural. Tese, FE/Unicamp, Campinas, 1987.

SAVIANI, D. História das idéias pedagógicas no Brasil. Campinas: Autores Associados, 2007.

SILVA, Ruth Ivoty Torres da. A escola primária rural. Porto Alegre: Editora Globo, 1970.

SOUZA, Maria Antônia de. A formação da Identidade Coletiva: Um estudo das lideranças de assentamentos rurais no pontal do paranapanema. Campinas: Universidade Estadual de Campinas. Faculdade de Educação, 1994.

TOURAINE, A. O retorno do actor: ensaio sobre sociologia. Lisboa, Portugal: Instituto Piaget, 1984.

\footnotetext{
${ }^{1}$ Doutor em Educação pela Unicamp. Professor adjunto da Universidade Federal de São Carlos-UFSCar. Membro do Grupo de Estudos e Pesquisas "História, Sociedade e Educação" - HISTEDBR.

${ }^{2}$ Doutora em Educação pela Unicamp. Professora adjunta do Departamento de Educação na Universidade Federal de São Carlos- UFSCAR. Coordenadora do Grupo de Estudos e Pesquisas "História, Sociedade e Educação" - HISTEDBR.

3 Programa Nacional de educação na Reforma Agrária, criado em 1998, com a função de investir na formação de jovens e adultos, visando diminuir os índices de analfabetismo no campo, tem exercido importante papel na formação de professores, sobretudo através da chamada pedagogia da terra.
}

Recebido dia 10/03/2010

Avaliado dia 20/05/2010

Revista HISTEDBR On-line, Campinas, número especial, p.251-272, ago.2010 - ISSN: 1676-2584 272 